\title{
Quantification of the distal radial artery for improved vascular access
}

\author{
E. Wessel, K. Hessel, A. Glaros, A. Olinger \\ Kansas City University of Medicine and Biosciences, Kansas City, MO, United States
}

[Received 13 May 2014; Accepted 1 July 2014]

Background: There is no consensus in the literature as to which point of the radial artery (RA) is the safest to attempt vascular access. The purpose of this study was to measure the diameter, tortuosity and branching patterns of the distal RA. Materials and methods: 140 cadaveric RAs (66 male, 74 female) were dissected and measured. The external diameter of the $R A$ was measured at $2 \mathrm{~cm}$ increments starting at the radial styloid process (SP), moving proximally. The location and degree of 2-dimensional arterial tortuosity were recorded if $>35$ degrees. Branches of the RA were recorded with respect to their distance from the SP.

Results: We observed that the right RA significantly increased in diameter at distances beyond $4 \mathrm{~cm}$ proximal from the radial $S P$, regardless of the sex of the individual. This increase in size was not noted on the left RA's. Muscular artery branches of the distal RA were noted on average $1.82 \mathrm{~cm}$ proximal from the $S P$. Clinically significant tortuosity was present on average $3.47 \mathrm{~cm}$ proximal from the radial SP. The left RA did not significantly change in size along its course, but its statistically similar diameter when compared to the right RA allows us to make a recommendation this is applicable bilaterally.

Conclusions: Our data suggests that regardless of gender, vascular access of the RA could be safely performed at distances greater than $4 \mathrm{~cm}$ from the SP to yield a vessel with a larger diameter, less tortuosity, and fewer branches. (Folia Morphol 2015; 74, 1: 100-105)

Key words: percutaneous coronary intervention, catheterisation, trans-radial

\section{INTRODUCTION}

Physicians have long utilised the radial artery (RA) as a means for obtaining arterial vascular access but the versatility of the RA has traditionally been limited to drawing arterial blood gases [7] and placing intra-arterial blood pressure monitors [2]. However, recent years have seen an increase in use of the RA for percutaneous coronary interventions $(\mathrm{PCl})$ as a safe alternative to traditional catheterisation techniques that utilise the femoral or brachial arteries $[1,3,9$, $14,15,20,21]$.
The RA is one of two terminal branches of the brachial artery (Figs. 1, 2). Classically the brachial artery crosses the anterior aspect of the elbow joint, enters the cubital fossa and bifurcates into the radial and ulnar arteries. The RA then courses laterally and continues distally down the forearm, paralleling the superficial radial nerve as it runs deep to the medial edge of the brachioradialis muscle. As the muscle belly of the brachioradialis tapers into its tendon the RA emerges superficially, running superomedially to the tendon of the brachioradialis muscle and lateral

Address for correspondence: Dr E.M. Wessel, Department of Anatomy, Kansas City University of Medicine and Biosciences, 1750 Independence Ave., Kansas City, MO 64106, USA, tel: (402) 926-8938, e-mail: ewessel@kumc.edu 


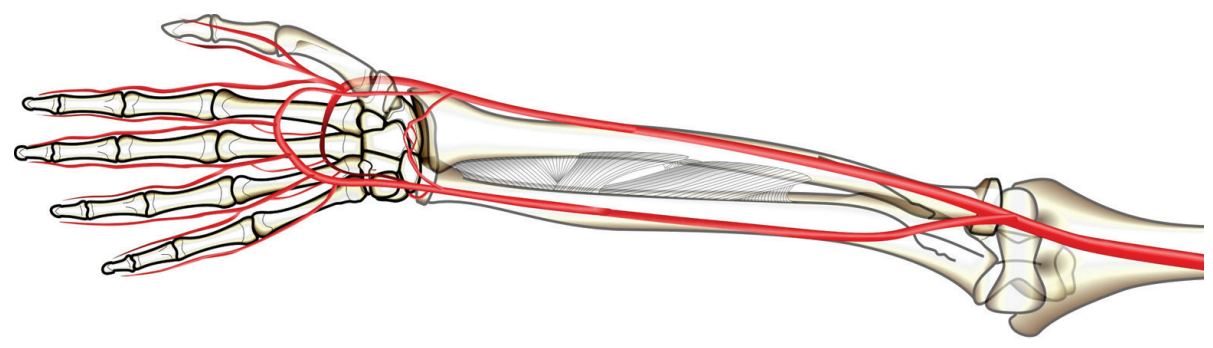

Figure 1. Schematic representation of the brachial, radial, and ulnar arteries. Note the presence of a superficial palmar branch of the radial artery.

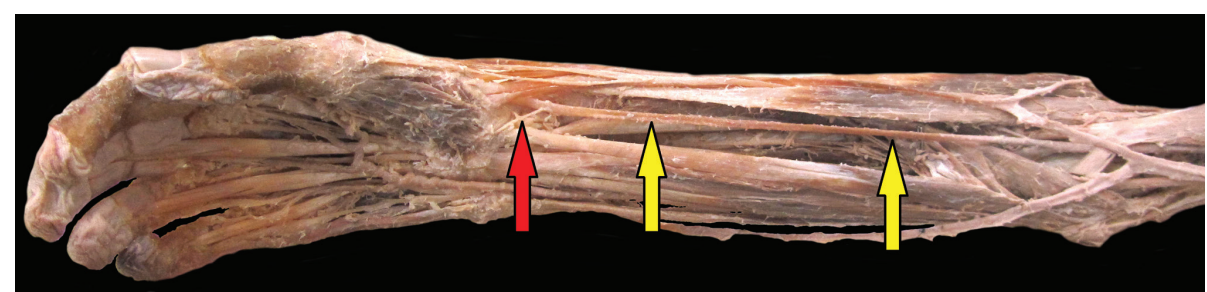

Figure 2. Cadaveric specimen highlighting the radial artery (yellow arrows) as it runs deep to the brachioradialis muscle. Note the superficial radial artery (red arrow).

to the tendon of the flexor carpi radialis muscle, while the superficial radial nerve transitions to a more lateral position. The RA then runs deep to the palmar carpal ligament, and after passing the radial styloid process, courses through the anatomical snuff box to anastomose with the ulnar artery via the deep and superficial palmar arches [17].

The course of the RA as it emerges from under the belly of the brachioradialis muscle and approaches the wrist provides a target vessel that is both superficially located and relatively devoid of major surrounding neurovascular structures $[1,9,17,21]$. Thus arterial access via the RA offers the advantage of increased ease of vascular access, increased ability to provide haemostasis, and decreased rates of access site complications including bleeding and haematoma development, arteriovenous fistula formation, aneurysm, limb ischaemia and nerve damage when compared to transbrachial or transfemoral approaches $[1,3,9$, $10,14,18,19,26,28]$. RA cannulation for $\mathrm{PCl}$ also touts improved patient tolerance, decreased length of patient hospital stay, decreased medical expenses $[1,3,5,18,20,21]$, decreased nursing work-load $[14,18]$ and decreased time to ambulation post procedurally $[1,3,14,15,19,20,21,26,27]$ when compared to transbrachial or transfemoral approaches. Despite the rising use of the RA for vascular access, there is little consensus in the literature as to which point of the RA is the most appropriate site for cannulation. The literature recommends cannulation anywhere from just proximal to the radial styloid [9], to $2 \mathrm{~cm}$ proximal to the radial styloid process $[6,10]$ and $2-3 \mathrm{~cm}$ proximal from the flexural crease of the wrist $[12,20]$ with little or no objective justification as to why these are the preferred sites. The presence of anatomic variations in the radial artery such as hypoplastic RAs, tortuosity greater than 35-45 degrees or abnormal branching patterns have all been associated with failure to puncture the RA, vasospasm and increased negative outcomes during attempted transradial-PCl including procedure failure $[1,6,11,13,14,18,24,28]$ but the literature fails to objectively take these factors into account when making suggestions for appropriate vascular entry sites. The goal of our research is thus to quantify the anatomy of the distal RA in hopes of elucidating the most appropriate location to attempt to vascular access.

\section{MATERIALS AND METHODS}

One hundred forty embalmed cadaveric RAs ( 66 male, 74 female) were dissected utilising standard dissection techniques to gain access to the anterior compartment of the forearm and lateral compartment of the wrist to observe and measure the RA. 
Table 1. Average diameter of right and left radial arteries in centimetres at increasing increments from the radial styloid process using combined data of both sexes. Standard deviations for each increment are also given

\begin{tabular}{lccccc}
\hline & \multicolumn{3}{c}{ Right } & & \multicolumn{2}{c}{ Left } \\
\cline { 2 - 3 } \cline { 5 - 6 } & Mean [cm] & Standard deviation & & Mean [cm] & Standard deviation \\
\hline Styloid & 0.74282 & 1.129677 & & 0.77539 & 1.183398 \\
$2 \mathrm{~cm}$ & 0.77027 & 1.105098 & & 0.80520 & 1.208126 \\
$4 \mathrm{~cm}$ & 0.79703 & 1.147195 & & 0.76762 & 1.108850 \\
$6 \mathrm{~cm}$ & 0.82856 & 1.199831 & & 0.76412 & 1.086082 \\
$8 \mathrm{~cm}$ & 0.83678 & 1.221161 & & 0.74292 & 1.050940 \\
$10 \mathrm{~cm}$ & 0.90242 & 1.283652 & & 0.82711 & 1.136040 \\
\hline
\end{tabular}

Care was taken to remove all fascia and adventitia from the surface of each artery. Mitutoyo digital callipers were used to measure the greatest external diameter of the RA in a relaxed, circular shape at $2 \mathrm{~cm}$ increments starting at the radial styloid process, moving proximally, paralleling the long axis of the radius. The location and degree of 2 -dimensional tortuosity of the artery were recorded if clinically significant (i.e. greater than 35 degrees) as measured with a goniometer. Muscular artery branches of the RA were recorded with respect to their distance from the radial styloid process. Cadaveric samples were excluded from data analysis if embryologic variation (e.g. high bifurcating brachial artery, etc.), surgical/pathologic phenomena (e.g. dialysis related AV-fistula, etc.) were present and thought to alter the course or composition of the RA.

All statistical analyses were carried out using Microsoft Excel and IBM SPSS V2.0 software. Descriptive statistics were generated to yield the minimum, maximum, mean and standard deviation of all measurements at each specified interval on the RA.

Finally, using a general linear model for repeated measures (ANOVA), the incremental measurements of the RA were compared to the measurements at the styloid processes both with and without sex as a between-subjects factor. Contrasts comparing diameters at increasing distances from the styloid process were also obtained.

\section{RESULTS}

\section{Arterial diameter}

Statistical analysis showed right RAs significantly increased in size at all intervals beyond $4 \mathrm{~cm}$ proximal from the radial styloid process $(p<0.005)$. Left RAs did not significantly increase in size as the distance

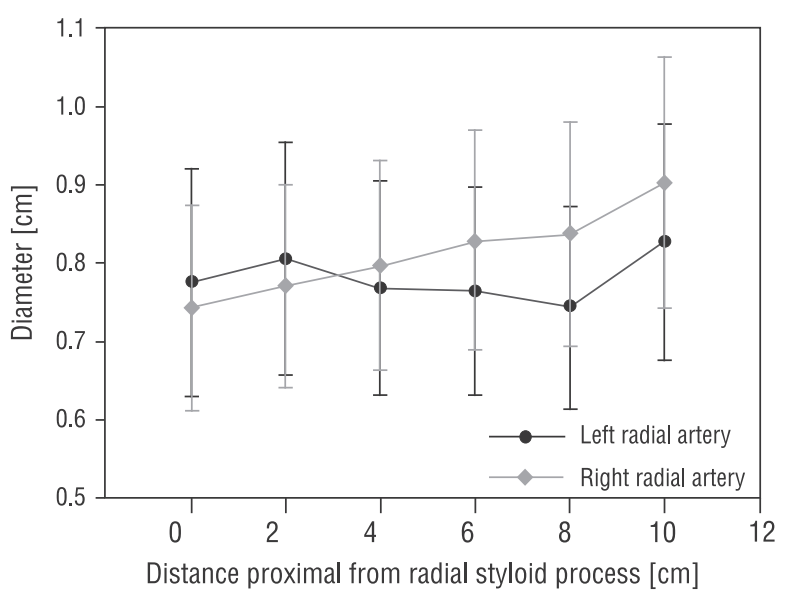

Figure 3. Average radial artery diameters with standard error bars.

from the radial styloid process increased. Right RAs were also found to be significantly larger than left RAs at the $8 \mathrm{~cm}$ increment $(p<0.04)$. The sex of the cadavers studied was found not to contribute to these differences.

Repeated measures analysis of variance on diameters from the right side showed a significant main effect of distance $(F(5,310)=5.497, p<0.001$, partial $\eta^{2}=0.081$ ). Contrasts were performed, comparing artery diameters at the right styloid process to diameters at increasing distances from the right styloid process. These contrasts showed significant ( $p<0.005)$ differences in diameters at 6,8 , and $10 \mathrm{~cm}$ from the right styloid process (partial $\eta^{2}=0.119$, 0.127 , and 0.155 , respectively). A similar analysis using left RA diameters did not show significant effects. Sex and the interaction of sex with distance did not account for significant proportions of the variance. Table 1 contains RA diameters by side and distance from the styloid process. Figure 3 displays the average diameter and standard errors of the right 
and left RA moving proximally away from the radial styloid process.

\section{Arterial branching}

Seventy-nine per cent of all cadavers studied had at least one muscular artery branch that came off of either RA $(n=64)$. Sixteen per cent of cadavers studied had one or more muscular arteries branching off of the RA bilaterally $(n=17)$ and $7 \%$ of cadavers studied had two or more muscular arteries branching off of a RA $(n=6)$. Between males and females collectively, $65 \%$ of right RAs $(n=48)$ and $48 \%$ of left RAs $(n=32)$ had at least one muscular artery branch. These arterial branches occurred on average $1.91 \mathrm{~cm}$ and $1.70 \mathrm{~cm}$ from the radial styloid process on the right and left, respectively.

In males $48 \%$ of RAs studied had at least one muscular artery branch $(n=32)$ with $9 \%$ having muscular arterial branches present bilaterally $(n=6)$ and $4 \%$ having multiple branches unilaterally $(n=3)$. Branches were present in $40 \%$ of left $(n=12)$ and $72 \%$ of right $(n=20)$ RAs in males. In addition, muscular artery branching in males occurred on average $1.82 \mathrm{~cm}$ from the radial styloid process $(\mathrm{n}=46)$ with the average branching distance being $1.51 \mathrm{~cm}$ and $1.94 \mathrm{~cm}$ for the left $(n=16)$ and right $(n=30)$ RAs, respectively.

In females $41 \%$ of RAs studied had at least one muscular artery branch $(n=30)$ with $12 \%$ having branches bilaterally $(n=9)$ and $1 \%$ having multiple branches unilaterally $(n=1)$. Arterial branches were present in $54 \%$ of left $(n=20)$ and $59 \%$ of right $(n=22)$ RAs in females. In addition, muscular artery branching occurred an average of $1.86 \mathrm{~cm}$ from the radial styloid process $(n=43)$ with the averages being $1.86 \mathrm{~cm}$ and $1.87 \mathrm{~cm}$ for branches of the left $(\mathrm{n}=20)$ and right $(n=23)$ RAs, respectively.

\section{Arterial tortuosity}

Clinically significant arterial tortuosity $\left(\geq 35^{\circ}\right)$ was present in $37 \%$ of all cadavers studied $(n=30)$ with $20 \%$ of cadavers having multiple arterial tortuosities unilaterally $(n=17)$ and $2 \%$ of cadavers showing tortuosity bilaterally $(n=2)$. Pooled measurements of males and females found tortuosity occurred on average $3.47 \mathrm{~cm}$ from the radial styloid process. In males tortuosity was present in $28 \%$ of right RAs $(n=10)$ and $27 \%$ of left RAs $(n=8)$ with tortuosity occurring on average $3.65 \mathrm{~cm}$ from the radial styloid process. In females tortuosity was present in $30 \%$ of right RAs ( $n=11)$ and $22 \%$ of left RAs $(n=8)$ with tortuosity occurring on average $3.31 \mathrm{~cm}$ from the radial styloid process.

\section{DISCUSSION}

In addition to the frequent use of the RA for drawing arterial blood gases and intra-arterial pressure monitoring, studies have demonstrated that there are many potential benefits of achieving arterial access through a transradial approach when compared to traditional transfemoral or transbrachial procedures $[1,3,9,10,18,19,20,26,28]$. However, some researchers have shown that the transradial approach is associated with increased rates of procedural failure overall [8]. Undoubtedly, the relatively limited use of transradial-PCl in the United States more than likely contributes to the increased failure rates but whether this is owing to operator inexperience, or strictly to anatomic limitations is yet to be determined. Given that the right RA significantly increased in diameter at distances greater than $4 \mathrm{~cm}$ from the radial styloid process, we suggest that many of the recommended insertion points currently listed in the literature, be it just proximal to the radial styloid [9], $2 \mathrm{~cm}$ proximal to the radial styloid process $[6,10]$ or $2-3 \mathrm{~cm}$ proximal from the flexural crease of the wrist $[12,20]$, are unintentionally making the process of RA cannulation more difficult owing to the smaller size of the vessel near the radial styloid process. Similarly, given that accessory arterial branches which are associated with increased negative outcomes during transradial-PCl occurred on average $1.91 \mathrm{~cm}$ and $1.70 \mathrm{~cm}$ from the radial styloid process (on the right and left, respectively), the currently recommended cannulation sites are again in potentially problematic areas. This is especially true when considering the high prevalence of muscular artery branches we noted coming from the distal RA. Lastly, since we found that clinically significant arterial tortuosity $\left(\geq 35^{\circ}\right)$ was present at an average distance of $3.47 \mathrm{~cm}$ from the radial styloid process, we believe that all currently recommended cannulation sites are likely to encounter these anatomical problems. The presence of arterial tortuosity in close proximity to the wrist likely allows the RA to accommodate to any stretch and strain it may encounter during flexion/extension, and abduction/adduction and though significant tortuosity can occur at any point along the course of the RA it appears they more often occur near the wrist thus making the distal RA near the styloid process a less suitable site for attempted vascular access. 
With the above information in mind, we suggest that attempts at RA vascular access could be safely and successfully performed at distances beyond $4 \mathrm{~cm}$ proximal from the radial styloid process. This distance takes into consideration not only the larger diameter of the artery at the point of entry, but the decreased incidence of arterial branches and tortuosity that have been associated with procedure failure during transradial-PCl. Given that the increase in size of the right RA occurred regardless of the sex of the individual we would make this recommendation for both genders. Even if the current recommended sites for RA vascular access remain the standard practice, our research is the first to objectively support the practice that failure to cannulate the RA near the radial styloid process merits investigation of the RA more proximally, either with additional attempts at cannulation or via ultrasound imaging. Although the left RA did not significantly increase in size at any of the intervals we studied it should be noted that the diameter of right and left RAs were only significantly different at the $8 \mathrm{~cm}$ interval. Therefore, even though the left RA did not show an upward trend in diameter as was noted on the right side, we still feel that anatomical hurdles in accessing the left RA could be avoided if vascular access is attempted beyond $4 \mathrm{~cm}$ from the radial styloid process.

Interestingly, during the course of our investigation we found 3 cadavers displayed high bifurcation of the brachial artery either unilaterally $(n=2)$ or bilaterally $(n=1)$. Although this data was excluded from our statistical analysis because these variations were considered to be confounding variables, it brings up an important area for future investigations. High branching brachial arteries, and similar variations are the most frequently mentioned RA variants listed in the literature $[4,16,23-25]$ but for the most part these do not appear to alter the course of the distal RA. However, several authors have noted that anatomic variations including high bifurcation of the brachial artery, and radio-ulnar loops, (in addition to the 3 variables covered in our paper) do in fact increase procedure time $[24,28]$. Furthermore, one author suggests that insufficiency of certain vascular networks can promote the expansion of superficial vessels in the forearm which can prove confusing for practitioners [4]. In addition to reports of high bifurcation of the brachial artery case reports of the RA arising from the thoracoacromial trunk can be found in the literature [22], but the infrequency of such anomalies makes clinical correlations (beyond case reports) difficult.

\section{Limitations of the study}

A potential limitation of this study was that accurate measurement of the internal diameter of the RA was not feasible. Future investigations, histologic or otherwise would likely be beneficial in that it could correlate the measured external diameter to the diameter of the lumen that is being catheterised. Some investigators have suggested the ulnar artery as a primary access site for $\mathrm{PCl}$ [28], or following failed attempts to cannulate the RA [3]. In any case, much like the transradial vascular access, further characterisation of the ulnar artery would likely prove beneficial for procedures that utilize this artery. Lastly, given that right handedness is more prevalent in the general population, our data may suggest that there is a handedness component to our results. Notably, we observed a higher prevalence of muscular arteries branching from right versus left RAs, as well as the significant diameter changes noted previously. However, the handedness data of the cadavers we studied was unobtainable, though this may be a logical next step for future investigation.

\section{REFERENCES}

1. Agostoni P, Biondi-Zoccai GG, de Benedictis ML, Rigattieri $S$, Turri M, Anselmi M, Vassanelli C, Zardini P, Louvard $Y$, Hamon M (2004) Radial versus femoral approach for percutaneous coronary diagnostic and interventional procedures. J Am Coll Cardiol, 44: 349-356.

2. Alarcon L, Fink MP (2010) Chapter 13. Physiologic monitoring of the surgical patient. In: Brunicardi FC, Andersen DK, Billiar TR, Dunn DL, Hunter JG, Matthews JB, Pollock RE, eds. Schwartz's principles of surgery. 9th Ed. McGraw-Hill, New York.

3. Archbold RA, Robinson NM, Schilling RJ (2004) Radial artery access for coronary angiography and percutaneous coronary intervention. Br Med J, 329: 443-446.

4. Bailleul JP (2014) Variations of the radial artery in man. Surgical Radiologic Anat, 22: 299-303.

5. Barbeau G, Carrier G, Ferland S, Letourneau L, Gleeton O, Lariviere MM (1996) Right transradial approach for coronary procedures: preliminary results. J Invasive Cardiol, Suppl. D: 19D-21D.

6. Bilodeau M (2010) Transradial basics: a practical approach to coronary catheterization and intervention via the radial artery. Cardiac Interventions Today, 25-32.

7. Brown A, Sweeney DB, Lumley J (1969) Percutaneous radial artery cannulation. Anasthesia, DOI: 10.1111/j.13652044.1969.tb02906.x.

8. Brueck M, Bandorski D, Kramer W, Wieczorek M, Höltgen R, Tillmanns H (2009) A randomized comparison of transradial versus transfemoral approach for coronary angiography and angioplasty. J Am Coll Cardiol, 2: 5048-5054. 
9. Campeau L (1989) Percutaneous radial artery approach for coronary angiography. Catheter Cardiovasc Interv, 16: 3-7.

10. Caputo RP, Tremmel JA, Rao S, Gilchrist IC, Pyne C, Pancholy S, Frasier D, Gulati R, Skelding K, Bertrand O, Patel T (2011) Transradial arterial access for coronary and peripheral procedures: executive summary by the transradial committee of the SCAI. Catheter Cardiovasc Interv, 78: 823-839.

11. Chandarana A, Baxi H (2010) Anatomical considerations in transradial intervention. Indian Heart J, 62: 211-213.

12. Danckers M (2011) Arterial Blood Gas Sampling. Medscape. Web. 22 Feb. 2013. http://emedicine.medscape. com/article/1902703-overview.

13. Dehghani $P$, Mohammad $A$, Bajaj $R$, Hong $T$, Suen $C M$, Sharieff W, Chisholm RJ, Kutryk MJ, Fam NP, Cheema AN (2009) Mechanism and predictors of failed transradial approach for percutaneous coronary interventions. J Am Coll Cardiol, 2: 1057-1064.

14. Eccleshall SC, Banks M, Carroll R, Jaumdally R, Fraser D, Nolan J (2003) Implementation of a diagnostic and interventional transradial programme: resource and organizational implications. Heart, 89: 561-562.

15. Grinfiled L, Berrocal D, Rojas Matas C, Magm J, Belardi J (1996) What is the most effective vascular approach for a diagnostic cardiac catheterization? A randomized trial using the femoral, brachial or radial approaches. J Am Coll Cardiol, 27: 17.

16. Jurjus A, Sfeir R, Bezirdjian R (1986) Unusual variation of the arterial pattern of the human upper limb. Anat Rec, 215: 82-83.

17. Jyothsna P, Nayak SB, Mohandas Rao KG, Kumar N, Abhinitha $P$ (2013) High level branching and very superficial course of radial artery in the anatomical snuffbox: its clinical and surgical implications. OA Case Reports, 2: 66.

18. Kanei Y, Kwan T, Nakra NC, Liou M, Huang Y, Vales LL, Fox JT, Chen JP, Saito S (2011) Transradial Cardiac Catheterization:
A Review of Access Site Complications. Catheter Cardiovasc Interv, 78: 840-846.

19. Kanjanauthai S, Napier R, Raja T, Arora V (2011) Transradial versus transfemoral approach in coronary angiography and intervention: literature review. Cardiac Cath Lab Director, 1: 28-30.

20. Kedev S (2011) Transradial and transulnar access for percutaneous coronary interventions. Turk Kardiyol Dern Ars, 39: 332-340.

21. Kiemeneij F, Laarman GJ, Odekerken D, Slagboom T, van der Wieken $\mathrm{R}$ (1997) A randomized comparison of percutaneous transluminal coronary angioplasty by the radial, brachial and femoral approaches: the access study. J Am Coll Cardiol, 29: 1269-1275.

22. Loukas M, Louis RG Jr, Almond J, Armstrong T (2005) A case of an anomalous radial artery arising from the thoracoacromial trunk. Surg Radiol Anat, 27: 463-466.

23. Nasr AY (2013) The radial artery and its variations: anatomical study and clinical implications. Folia Morphol, 71: 252-262.

24. Nie B, Zhou YJ, Li GZ, Shi DM, Wang JL (2009) Clinical study of arterial anatomic variations for transradial coronary procedure in Chinese population. Chinese Med J, 122: 2097-2102.

25. Pelin C, Zagyapan R, Karabay G (2014) An unusual course of the radial artery. Folia Morphol, 65: 410-413.

26. Rao SV, Cohen MG, Kandzari DE, Bertrand OF, Gilchrist IC (2010) The transradial approach to percutaneous coronary intervention: historical perspective, current concepts, and future directions. J Am Coll Cardiol, 55: 2187-2195.

27. Schussler JM (2011) Effectiveness and safety of transradial artery access for cardiac catheterization. Baylor University Medical Center Proceedings, 24: 206-209.

28. Valsecchi O (2006) Failure of transradial approach during coronary interventions: anatomic considerations. Catheterization Cardiovascular Interventions, 67: 870-878. 